\title{
Liver cytosolic 1 antigen-antibody system in type 2 autoimmune hepatitis and hepatitis $C$ virus infection
}

\author{
M Lenzi, P Manotti, L Muratori, M Cataleta, G Ballardini, F Cassani, F B Bianchi
}

\begin{abstract}
Within the multiform liver/kidney microsomal (LKM) family, a subgroup of sera that reacts with a liver cytosolic (LC) protein has been isolated and the new antigen-antibody system is called LC1. Unlike LKM antibody type 1 (anti-LKM1), anti-LC1 is said to be unrelated to hepatitis $\mathrm{C}$ virus (HCV) infection and has therefore been proposed as a marker of 'true' autoimmune hepatitis type 2. Altogether 100 LKM1 positive sera were tested by immunodiffusion (ID). Twenty five gave a precipitation line with human liver cytosol; 17 of the 25 also reacted with rat liver cytosol. Thirteen of the 25 sera were anti-HCV positive by second generation ELISA: anti-HCV positive patients were significantly older $(p<0.001)$ and tended to have less active disease. No difference in anti-LC1 titre or ID immunoreactivity was found between anti-LC1/anti-HCV positive and anti-LC1/anti-HCV negative cases. In Western blotting experiments, 14 of 24 ID positive sera recognised a $58 \mathrm{kD}$ protein of the human cytosolic fraction and 11 gave a similar reactivity when tested with human microsomes, suggesting the presence of the LC1 target antigen also in the microsomal preparation. Western blotting reactivity was similar for both anti-HCV positive and negative sera. These data confirm the existence of the LC1 antigen-antibody system that partially overlaps with LKM1, and that it is an additional marker of juvenile autoimmune hepatitis type 2 . It does not, however, discriminate between patients with and without $\mathrm{HCV}$ infection.

(Gut 1995; 36: 749-754)
\end{abstract}

Keywords: liver/kidney microsomal antibody type 1 , liver cytosolic antigen - antibody, hepatitis $C$ virus, autoimmune hepatitis type 2 .

Type 2 autoimmune hepatitis was proposed as a clinical entity in 1987 by Homberg et al in a series of patients with chronic active hepatitis of unknown origin associated with serum liver/kidney microsomal antibody type 1 (antiLKM1). ${ }^{1}$ Nearly half of the patients considered in the study were under the age of 14 and the authors postulated an immunological aetiology largely on the basis of the data obtained from this younger subset of patients.

In 1990-91 we showed that most Italian adults with anti-LKM1 positive chronic hepatitis are positive both for antibodies to the newly discovered hepatitis $\mathrm{C}$ virus $(\mathrm{HCV})^{2} 3$ and for serum HCV RNA. ${ }^{4}$ These data were confirmed by Lunel et al, ${ }^{5}$ who added the important observation that, unlike the adult disease, the childhood-juvenile form of antiLKM1 positive chronic hepatitis is remarkably free from $\mathrm{HCV}$ infection. As a consequence, the diagnosis of type 2 autoimmune hepatitis has mainly been confined to a rare chronic active liver disease of unknown aetiology, characterised by female predominance, young age at onset, and a frequent association with autoimmune disorders of other organs (endocrine pancreas, thyroid, skin). Both the biochemical and histological activity of type 2 autoimmune hepatitis are said to be high; untreated the disease runs a severe course, with a high rate of progression to liver cirrhosis. ${ }^{1}$ The clinical, biochemical, and histological picture closely resembles that of the classic autoimmune chronic active hepatitis seen in young women (so called 'lupoid' hepatitis), the differential peculiarity being that type 2 autoimmune hepatitis has a different autoantibody profile (anti-LKM1, instead of antinuclear or anti-actin antibodies, or both, which mark the classic type 1 autoimmune hepatitis).

In 1988 a second autoantibody marker of type 2 autoimmune hepatitis was recognised. This antibody, associated with anti-LKM1 in two thirds of positive cases, was found to react with an unidentified protein of liver cytosol and was therefore called anti-liver cytosol 1 (anti-LC1). ${ }^{6}$ Unlike anti-LKM1, anti-LC1 antibodies were never found in association with $\mathrm{HCV}$ infection and were therefore considered a more specific marker of type 2 autoimmune hepatitis than anti-LKM1. ${ }^{7}$

The present study assessed the relevance of anti-LKM1 and anti-LC1 in identifying type 2 autoimmune hepatitis in a retrospective series of 100 adults and children with anti-LKM1 positive chronic hepatitis. In particular, attention was focused on detecting a concomitant $\mathrm{HCV}$ infection.

\section{Methods}

\section{PATIENTS AND SERA}

Sera from 100 patients (of whom 83 were anti$\mathrm{HCV}$ positive) with chronic liver disease diagnosed according to internationally accepted criteria, ${ }^{8}$ assessed as anti-LKM1 positive on the basis of the immunofluorescent pattern, 


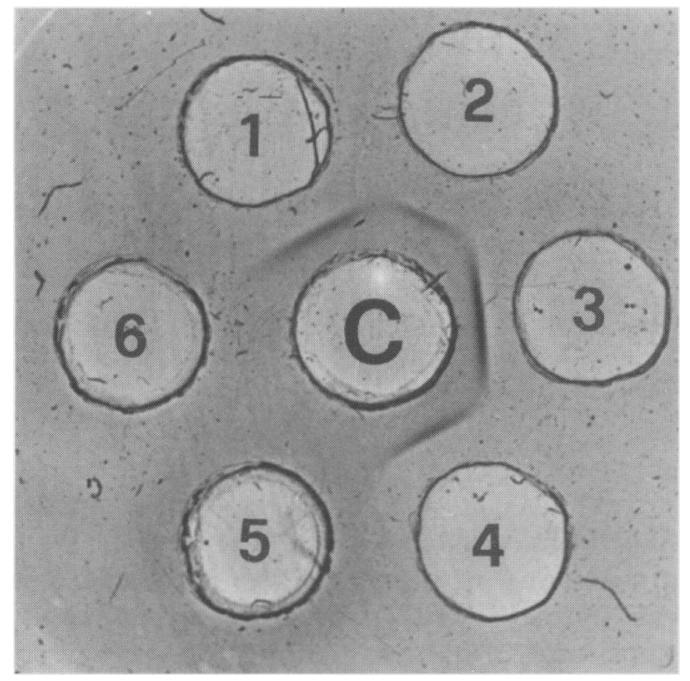

Figure 1: Immunodiffusion identity reaction of different liver cytosolic 1 antibody (anti-LC1) positive sera. Well $1=$ anti-LC1, hepatitis $C$ virus antibody (anti-HCV) positive serum. Well $2=$ reference serum.

Well 3=anti-LC1, liver/kidney microsomal antibody type 1 (anti-LKM1) positive, anti-HCV negative serum. Well $4=$ anti-LC1, anti-LKM1, anti-HCV positive serum. Well $5=$ anti-LKM1 positive, anti-HCV negative serum. Well 6=control serum. Well C=human liver cytosol.

were screened by immunodiffusion (ID) for the presence of anti-LC1.

Antibodies against $\mathrm{HCV}$ proteins (anti$\mathrm{HCV}$ ) were searched for by a commercially available second generation ELISA test (Ortho Diagnostic System, Raritan, NJ), according to the manufacturer's instructions, on serum samples stored at $-20^{\circ} \mathrm{C}$. The ELISA positivity was validated by RIBA 2 (Ortho). HCV RNA was searched for by 'nested' polymerase chain reaction (PCR) on seven (five anti-HCV positive and two anti-HCV negative) sterile serum samples using primers derived from the highly conserved $5^{\prime}$ non-coding region of the HCV genome. ${ }^{9}$ Liver histology was evaluated and classified as chronic hepatitis with mild/moderate activity or severe activity/ cirrhosis. Concomitant autoimmune disorders other than hepatitis were evaluated by clinical history.

Twenty five sera from patients with type 1 autoimmune hepatitis (positive for anti-actin or anti-nuclear antibodies, or both), 25 sera from patients with primary biliary cirrhosis, 20 sera from patients with autoantibody-negative chronic hepatitis C, and 25 sera from healthy blood donor were used as controls.

\section{IMMUNODIFFUSION}

Immunodiffusion was performed according to Martini et al. ${ }^{6}$ Liver cytosol and microsomes were prepared from the surgical specimens of a group $\mathrm{O}$ adult patient, $\mathrm{HBsAg}$ and anti-HCV negative, who had undergone partial hepatectomy for secondary liver deposits, and from male Sprague Dawley rats. Liver was homogenised with a Potter homogeniser in $0.25 \mathrm{M}$ sucrose Tris $\mathrm{HCl}, 2 \mathrm{mM}, \mathrm{pH} 7 \cdot 4$ at a dilution of 1:10 (w/v). After two hours of $105000 \mathrm{~g}$ ultracentrifugation, the supernatant was collected, dialysed overnight against PBS, and concentrated by centrifugation in an Amicon tube to a protein concentration of $20 \mathrm{mg} / \mathrm{ml}$. Pellets containing microsomal membranes were washed three times and resuspended in PBS at the same protein concentration.

The purity of the cytosolic fraction was controlled by electron microscopy. In particular, as previously described, ${ }^{10}$ no membranous structures were found in the cytosol by negative staining.

All sera were screened undiluted with human liver cytosol and the titres of those found positive were assessed by doubling the dilution to end point. Sera positive with human cytosol by ID were tested with rat cytosol and human and rat microsomes.

The immunological specificity of the reaction obtained by ID in our system was controlled by obtaining an identity reaction with a reference anti-LC1 positive serum, kindly provided by Professor J C Homberg (Paris).

\section{IMMUNOFLUORESCENCE AND ABSORPTION EXPERIMENTS}

Indirect immunofluorescence (IFL) was performed according to standard procedures on $5 \mu \mathrm{m}$ cryostat sections of rat liver and kidney with serum diluted 1:40 with PBS. The IFL pattern in each case was re-evaluated on the basis of the fluorescence observed on rat liver sections and scored as anti-LKM1 when the fluorescence was uniform throughout the liver lobule, or as anti-LC1 when the cytoplasmic staining spared two to three
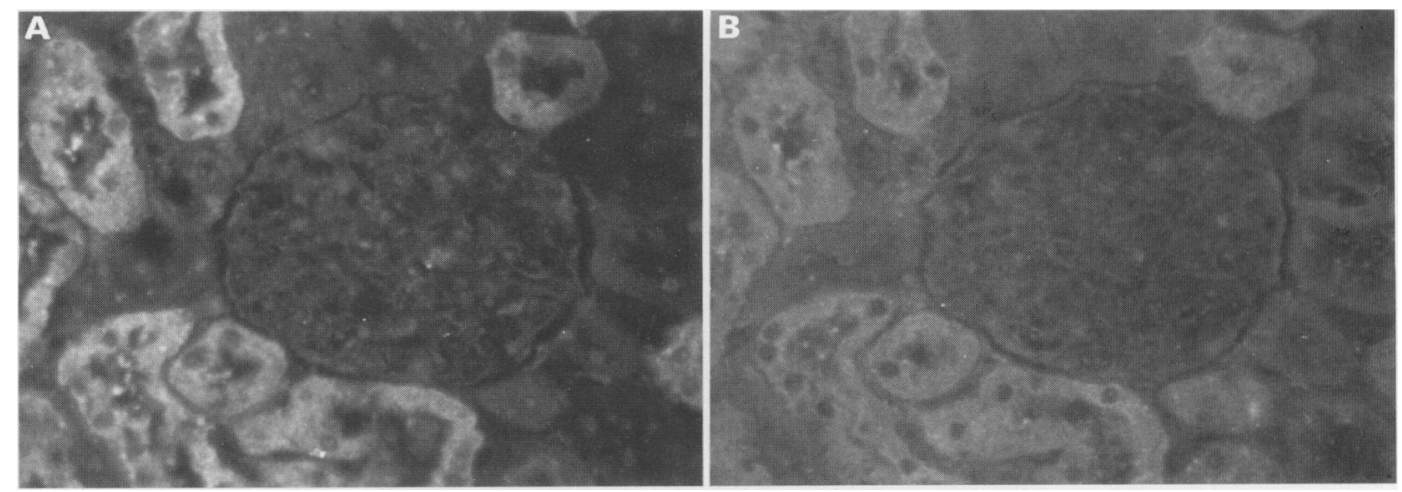

Figure 2: Indirect immunofuorescent (IFL) staining of consecutive rat kidney sections with a liver/kidney microsomal antibody type 1 (anti-LKM1) positive serum $(A)$, and with a liver cytosolic 1 antibody (anti-LC1) positive serum (B). The two sera shown were defined as anti-LKM1 or anti-LC1 according to the IFL pattern of rat liver (see text). The kidney pattern is the same, despite the diverse intensity of staining. (Original magnification $\times 25$.) 
TABLE I Clinical and immunological data for the 25 liver cytosolic 1 antibody (anti-LC1) positive patients

\begin{tabular}{|c|c|c|c|c|c|c|c|}
\hline No & Sex & Age (y) & ID titre & IB-cytosol & IB-microsomes & IFL pattern & Anti-HCV \\
\hline 1 & $\mathbf{M}$ & 8 & 1 & $58 \mathrm{kD}$ & $58 \mathrm{kD}$ & anti-LKM1 & - \\
\hline 2 & $\mathrm{~F}$ & 10 & 32 & $58 \mathrm{kD}$ & $58 \mathrm{kD}$ & anti-LC1 & - \\
\hline 3 & $\mathrm{~F}$ & 10 & 1 & - & $66 \mathrm{kD}$ & anti-LC1* & - \\
\hline 4 & $\mathrm{~F}$ & 10 & 8 & $58 \mathrm{kD}$ & - & anti-LC $1^{\star}$ & - \\
\hline 5 & $\mathrm{~F}$ & 15 & 64 & NT & NT & anti-LC1* & - \\
\hline 6 & $\mathrm{~F}$ & 15 & 128 & $58 \mathrm{kD}$ & $58,66 \mathrm{kD}$ & anti-LKM1 & - \\
\hline 7 & $\mathrm{M}$ & 16 & 128 & $58 \mathrm{kD}$ & $39,50,58 \mathrm{kD}$ & anti-LKM1 & - \\
\hline 8 & $\mathbf{M}$ & 18 & 4 & $58 \mathrm{kD}$ & $50,58,66 \mathrm{kD}$ & anti-LC1* & - \\
\hline 9 & $\mathrm{~F}$ & 21 & 4 & - & - & anti-LC ${ }^{\star}$ * & - \\
\hline 10 & $\mathrm{~F}$ & 25 & 16 & $58 \mathrm{kD}$ & $58 \mathrm{kD}$ & anti-LKM1 & - \\
\hline 11 & $\mathrm{~F}$ & 31 & 8 & - & $50 \mathrm{kD}$ & anti-LKM1 & - \\
\hline 12 & $\mathbf{F}$ & 40 & 1 & - & $39,50,66 \mathrm{kD}$ & anti-LKM1 & - \\
\hline 13 & $\mathrm{M}$ & 16 & 4 & - & $39,50 \mathrm{kD}$ & anti-LKM1 & + \\
\hline 14 & $\mathbf{F}$ & 17 & 128 & $58 \mathrm{kD}$ & $50,58,66 \mathrm{kD}$ & anti-LKM1 & + \\
\hline 15 & $\mathrm{M}$ & 19 & 512 & $58 \mathrm{kD}$ & - & anti-LKM1 & + \\
\hline 16 & M & 26 & 4 & $58 \mathrm{kD}$ & $39,50,66 \mathrm{kD}$ & anti-LKM1 & + \\
\hline 17 & $\mathbf{F}$ & 28 & 8 & - & $50 \mathrm{kD}$ & anti-LKM1 & + \\
\hline 18 & $\mathrm{~F}$ & 47 & 8 & - & $50 \mathrm{kD}$ & anti-LKM1 & + \\
\hline 19 & $\mathrm{~F}$ & 48 & 1024 & $58 \mathrm{kD}$ & $58 \mathrm{kD}$ & anti-LC $1^{\star}$ & + \\
\hline 20 & $\mathrm{~F}$ & 49 & 8 & $58 \mathrm{kD}$ & $58 \mathrm{kD}$ & anti-LC1* & + \\
\hline 21 & $\mathrm{~F}$ & 52 & 64 & $58 \mathrm{kD}$ & $50,58 \mathrm{kD}$ & anti-LC1* & + \\
\hline 22 & $\mathrm{~F}$ & 59 & 1 & - & - & anti-LKM1 & + \\
\hline 23 & $\mathrm{~F}$ & 59 & 2 & - & - & anti-LKM1 & + \\
\hline 24 & F & 62 & 2 & - & $50 \mathrm{kD}$ & anti-LKM1 & + \\
\hline 25 & $\mathrm{~F}$ & 63 & 1024 & $58 \mathrm{kD}$ & $58 \mathrm{kD}$ & anti-LC1* & + \\
\hline
\end{tabular}

$-=$ negative, $+=$ positive. ID: immunodiffusion; IB: Western immunoblotting with human cytosol and human microsomes; IFL: immunofluorescence pattern assessed on rat liver. $\mathrm{HCV}=$ hepatitis $\mathrm{C}$ virus, $\mathrm{NT}=$ not tested. ${ }^{\star}$ Coexistent typical liver/kidney microsomal antibody type 1 (anti-LKM1) renal staining.

layers of hepatocytes around the central vein.

Consecutive rat kidney sections were used to compare the IFL reactivity of sera giving the anti-LC1 or the anti-LKM1 pattern on rat liver.

Four sera that were anti-LC1 positive by ID - two giving an anti-LKM1 pattern and the remaining two giving an anti-LC1 pattern by IFL - were mixed at a dilution of $1: 10$ with an identical volume of either rat liver or rat kidney microsomes at a protein concentration of 20 $\mathrm{mg} / \mathrm{ml}$ and incubated overnight at $4^{\circ} \mathrm{C}$ on a rotor shaker. After centrifugation at $12000 \mathrm{~g}$ for 10 minutes both the supernatant and the original serum were tested by IFL on rat liver and kidney section at a final dilution of 1:40.

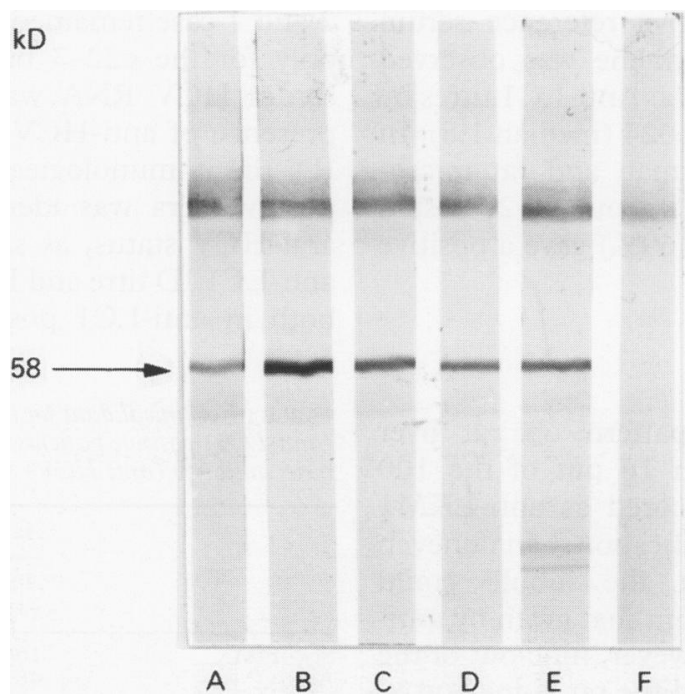

Figure 3: Immunoblotting experiments using human cytosol as the antigenic source. Lanes $A$ to $E$ : sera from patients with a positive immunodiffusion test with human cytosol. Lane F: second antibody (anti-human Ig) alone. An isolated single band at $58 \mathrm{kD}$ is present in all strips but $F$. Hepatitis $C$ virus antibody positive (lanes $A$ and $B$ ) and negative (lanes $C, D$, and $E$ ) show the same reactivity. In each strip a band at approximately $110 \mathrm{kD}$ (and a faint one at $52 \mathrm{kD}$ ) is due to human Ig present in the cytosolic preparation.

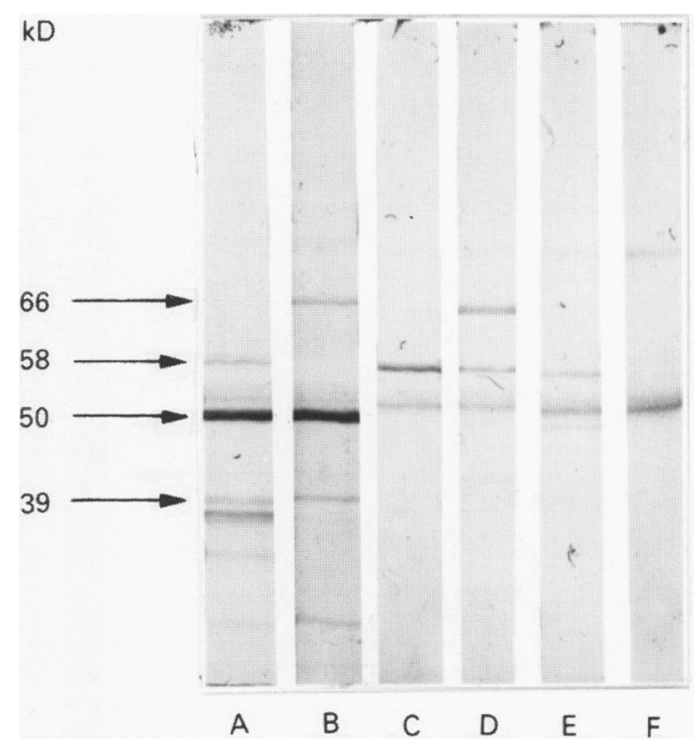

Figure 4: Immunoblotting experiments using human microsomes as antigenic source. Lanes $A$ to $E$ : sera from patients with positive immunodiffusion test with human cytosol (note that these sera are not the same as in Figure 1). Lane F: second antibody (anti-human Ig) alone. Heterogeneous patterns of reactivity are observed for both hepatitis $C$ virus antibody (anti-HCV) positive (strips $B$, $C$, and $E$ ) and anti-HCV negative sera (lanes $A$ and $D$ ). $A 50 \mathrm{kD}$ band, presumably corresponding to the main microsomal antigen cytochrome CYP2D6, is present in lanes $A, B$, and $E$. Other bands at $66 k D$ and $39 k D$ are also evident in lanes $B$ and $D$, and in $A$ and $B$, respectively. $A 58 \mathrm{kD}$ band is apparent in lanes $A, C, D$, and E. Reactivities at $52 \mathrm{kD}$ and at $110 \mathrm{kD}$ (faint) are due to human Ig present in the microsomal preparation.

\section{IMMUNOBLOTTING}

Immunoblotting (IB) was performed with 21 anti-LC1 positive and 45 anti-LKM1 positive/anti-LC1 negative sera, as described by Fusconi et al ${ }^{11}$ using human liver cytosol and microsomes as the source of antigen. Briefly, $400 \mu \mathrm{l}$ of a $1 \mathrm{mg} / \mathrm{ml}$ solution of cytosolic or microsomal proteins were separated by SDSPAGE in $10 \%$ polyacrylamide gel (Mini-PROTEAN II System, Bio-Rad Laboratories, Richmond, CA, USA) and transblotted onto nitrocellulose sheets which were then blocked with $3 \%$ dry milk powder in Tris buffer saline and cut into strips. Each strip was then incubated with patient or control sera at 1:100 dilution. Peroxidase-conjugate rabbit antihuman immunoglobulin (DAKO, Copenhagen, Denmark) at a dilution of 1:600 was used as second antibody.

The presence of CYP2D6, both in human microsomal and cytosolic fractions, was evaluated by IB with a monoclonal antibody (BI-114/2), kindly provided by Professor U A Meyer, Basel, Switzerland. ${ }^{12}$

Affinity purified antibodies eluted from a 58 $\mathrm{kD}$ cytosolic protein were retested against both microsomal and cytosolic proteins. To assess the specificity of the eluate the same affinity purification procedure was applied to a non-58 $\mathrm{kD}$ cytosolic protein.

\section{Results}

\section{IMMUNODIFFUSION}

Twenty five sera (25\%) of the 100 tested gave a precipitation line with the human cytosolic 


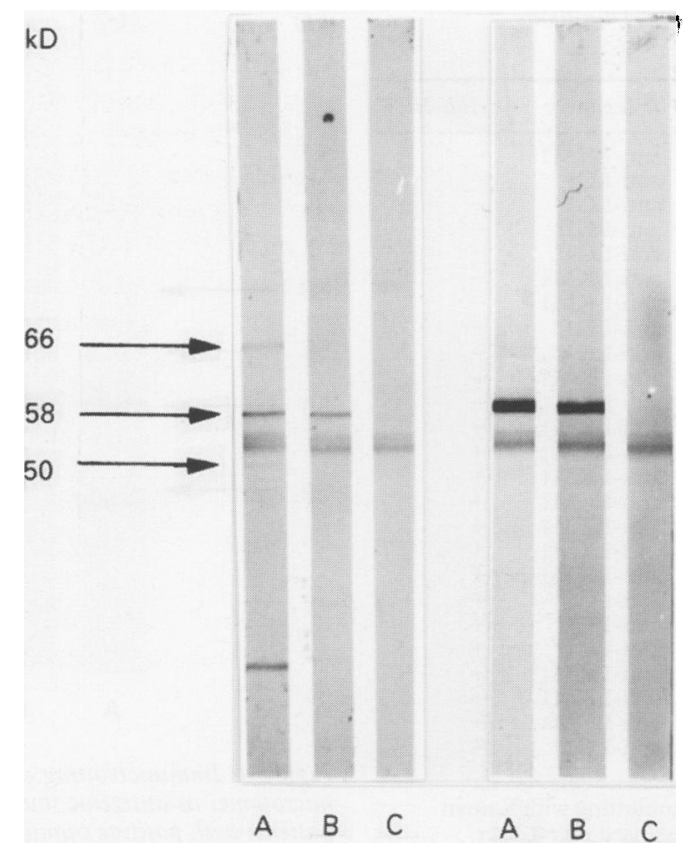

Figure 5: Nitrocellulose strips blotted with human microsomes (left) and human cytosol (right) were probed with total serum $(A)$, eluate from the cytosolic $58 \mathrm{kD}$ protein $(B)$, and eluate from cytosolic non-reactive proteins, as internal control of the elution procedure $(C)$. Total serum reacted with several microsomal proteins of 66 , 58, 50 (faint) kD; a band of approximately $20 \mathrm{kD}$, peculiar to this patient, is also evident. $A$ single $58 \mathrm{kD}$ band is present against the cytosolic fraction. Antibodies eluted from the $58 \mathrm{kD}$ cytosolic protein reproduced the 58 $k D$ reactivity on both microsomal (lane $B$, left) and cytosolic (lane B, right) substrates. The eluate obtained from the cytosolic non-reactive proteins tested negative (lanes $C$ ), as expected.

fraction; 17 out of the 25 sera also reacted with the rat liver cytosol. An identity reaction was observed when the 25 anti-LC1 positive sera were compared. The antigenic specificity of the precipitating antibody found in our sera is the same as that reported by Martini et al, ${ }^{6}$ as demonstrated by the identity reaction obtained with the anti-LC1 positive reference serum (Fig 1). No precipitation line was observed with any control group sera. Anti-LC1 titres by ID ranged from $1: 1$ to $1: 1024$ (median $1: 8$ ). In ID experiments with human and rat microsomes respectively, 19 sera out of 22 tested $(86 \%)$ and 17 out of $25(69 \%)$ gave a positive reaction.

\section{IMMUNOFLUORESCENCE}

The typical anti-LC1 pattern on rat liver sections was observed in 10 out of the 100 $(10 \%)$ sera previously scored as anti-LKM1 positive: at low magnification, an uneven fluorescence throughout the lobule could easily be distinguished from that given by antiLKM1 positive sera. However, nine out of the above 10 sera also stained the rat kidney proximal tubules, showing the typical anti-LKM1 pattern (Fig 2 panels (A) and (B)). When these 10 sera were tested by ID with either rat or human microsomes, all but the one giving no renal staining by IFL were reactive with at least one of the two microsomal preparations.

In the 15 cases deemed anti-LKM1 by IFL and giving a precipitation line with the human cytosol by ID, the absorption with either liver or kidney microsomes abolished the antiLKM1 reactivity from both liver and kidney sections, disclosing a previously masked antiLC1 pattern on the liver substrate. Accordingly, the renal staining of the nine sera scored as anti-LC1 on the liver sections disappeared after absorption with both liver and kidney microsomes, leaving unmodified the anti-LC1 pattern on rat liver.

\section{IMMUNOBLOTTING}

The monoclonal antibody $\mathrm{BI}-114 / 2$ reacted with a $50 \mathrm{kD}$ microsomal protein, corresponding to CYP2D6, but not with any of the cytosolic proteins.

Immunoblotting reactivity of 25 anti-LC1 positive sera is reported in Table I. Fourteen of the 24 sera tested $(58 \%)$ reacted with a human cytosolic protein of $58 \mathrm{kD}$ (Fig 3) and 11 of them showed a similar reactivity against human microsomes. The $58 \mathrm{kD}$ band was significantly associated with higher ID titres $(\mathrm{p}<0.001$ Wilcoxon rank sum test). Other reactivities at 39,50 , and $66 \mathrm{kD}$ were observed with human microsomes in $4(17 \%), 11$ (46\%), and 6 (25\%) sera, respectively (Fig 4).

No IB reaction with the $58 \mathrm{kD}$ cytosolic protein was observed with $45 \mathrm{LKM} 1$ positive/antiLC1 negative sera and with the control group sera.

Antibodies eluted from the $58 \mathrm{kD}$ protein of the liver cytosol reacted with a protein of the same molecular weight present both in human cytosol and human microsomes, as shown in Figure 5.

\section{CORRELATIONS WITH THE HCV STATUS}

Anti-HCV antibodies were found in 13 of 25 $(52 \%)$ anti-LC1 positive patients by second generation ELISA; 12 were validated by RIBA 2 and 1 case remained indeterminate (positive only for the c22-3 band). The detection of serum HCV RNA was concordant with the presence of anti-HCV in the cases tested. By ID, the immunological reactivity of anti-LC1 positive sera was identical regardless of the anti-HCV status, as shown in Figure 1. The anti-LC1 ID titre and IB reactivity were similar both in anti-LC1 positive/anti-HCV positive

TABLE II Clinical data for liver cytosolic 1 antibody (anti-LC1) positive patients according to the hepatitis $C$ virus antibody (anti-HCV) status.

\begin{tabular}{|c|c|c|}
\hline & \multicolumn{2}{|c|}{ Anti-LC1+ve $(n=25)$} \\
\hline & $\begin{array}{l}\text { Anti-HCV+ve } \\
(n=13)\end{array}$ & $\begin{array}{l}\text { Anti-HCV-ve } \\
(n=12)\end{array}$ \\
\hline 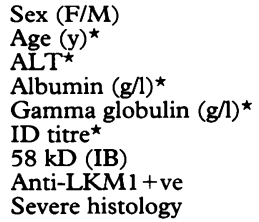 & $\begin{array}{l}10 / 3 \\
48(16-63) \\
2 \cdot 5(1-22) \\
38 \cdot 6(31-41 \cdot 7) \\
16 \cdot 6(10 \cdot 3-39) \\
8(1-1024) \\
7 / 13 \\
9 / 13 \\
5 / 12\end{array}$ & $\begin{array}{l}9 / 3 \\
15(8-40) \dagger \\
5 \cdot 5(1-29) \\
39 \cdot 1(37-46 \cdot 8) \\
19 \cdot 1(8 \cdot 4-27 \cdot 2) \\
8(1-128) \\
7 / 11 \\
6 / 12 \\
6 / 11\end{array}$ \\
\hline
\end{tabular}

^Median (range). $t \mathrm{p}<0 \cdot 001$.

ALT is given as times the upper normal limit.

ID $=$ immunodiffusion; anti-LKM1 = liver/kidney microsomal antibody type $1 ; \mathrm{IB}=$ immunoblotting. 

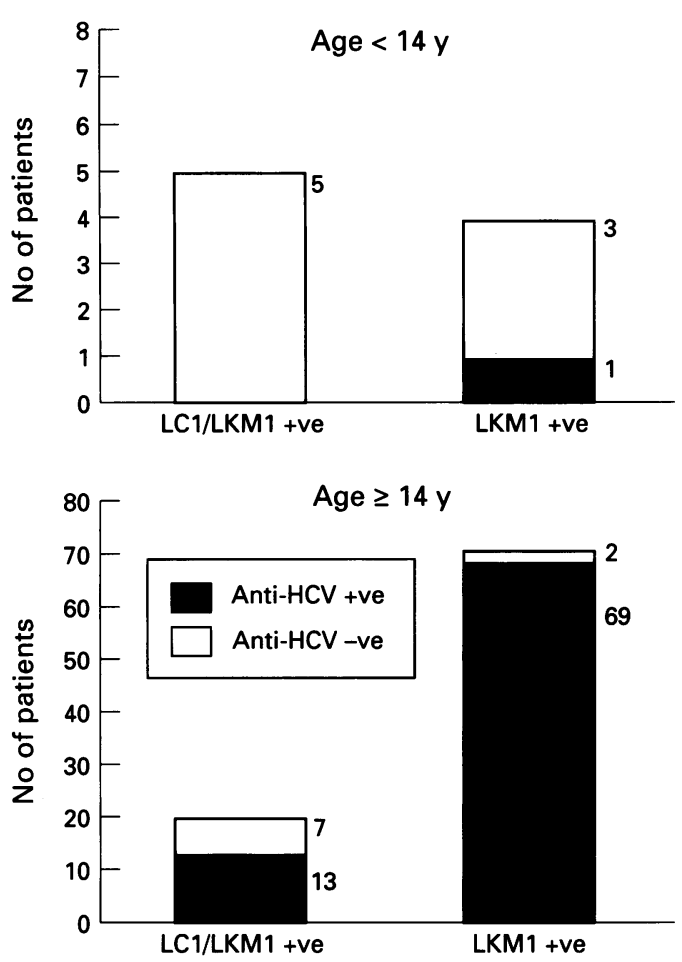

Figure 6: Age distribution of hepatitis $C$ virus (anti-HCV) antibody in liver/kidney microsomal antibody type 1 (anti-LKM1) /iver cytosolic 1 antibody (anti-LC1) positive cases and in isolated anti-LKM1 positive patients.

and in anti-LC1 positive/anti-HCV negative cases.

\section{CLINICAL CORRELATIONS}

Clinical and biochemical data for the anti-LC1 positive patients, classified according to the anti-HCV status, are listed in Table II. AntiHCV negative patients were significantly younger (median age 15 years, range 8-40 $v 49$ years, range 16-63; $p<0.001$ ), with higher ALT and gammaglobulin values, although such a difference did not reach statistical significance. Female preponderance was the same in the two groups. No difference could be demonstrated with respect to the severity of liver histology. Associated autoimmune disorders were present only in four anti-HCV negative patients (two with insulin dependent diabetes, one with an autoimmune thyroid disorder, and one with coeliac disease). None of the anti-HCV positive cases had risk factors for $\mathrm{HCV}$ infection.

The age distribution of the patients positive for both anti-LC1 and anti-LKM1 antibodies shows that the anti-LC1 antibody is never associated with anti-HCV reactivity in the paediatric patients. In contrast 13 of the 20 adults studied were positive for both anti-LC1 and anti-HCV (Fig 6).

\section{Discussion}

This study confirms that the LC1 antigen-antibody system is closely associated with LKM1 positive chronic hepatitis. Anti-LC1 detection is frequently missed in the routine IFL test since its specific immunomorphological pattern is masked by the coexistence of
anti-LKM1 antibody in the same serum. The specific anti-LC1 pattern can probably be recognised only when the anti-LC1 titre is higher than that of anti-LKM1. Careful evaluation of the IFL pattern on rat liver disclosed the typical anti-LC1 pattern in 10 of the 25 sera positive by ID for anti-LC1 and previously classified as anti-LKM1. The coexistence of anti-LKM1 in nine of these 10 sera, however, is suggested by at least three lines of evidence. The first is that the IFL positivity of renal tubules was, on consecutive sections, superimposable on that of anti-LKM1, and was specifically removed by absorption with both kidney and liver microsomal fractions. Secondly, the nine sera gave a positive immunoprecipitation line with rat or human liver microsomes, or both. Thirdly, several IB reactivities with human microsomes, typically associated with LKM1, were found in four of these nine sera (two at $50 \mathrm{kD}$ and two at $66 \mathrm{kD}$ ).

Immunoprecipitation therefore remains the test of choice for detecting anti-LC1; human cytosol turned out to be more sensitive than rat cytosol, which reacted only with $68 \%$ of the sera positive with the human substrate.

High titre anti-LC1 positive sera recognised a unique cytosolic polypeptide of $58 \mathrm{kD}$; a cross reactive protein of the same molecular weight was present in the microsomal preparation, as shown by the elution experiments. The $58 \mathrm{kD}$ reactivity detected in this study presumably corresponds to the $62 \mathrm{kD}$ band reported by Abuaf et al. ${ }^{7}$ This IB reactivity is strictly associated with a positive ID test for anti-LC1, since it has never been found in the 45 antiLKM1 positive/anti-LC1 negative sera tested. Whether this $58 \mathrm{kD}$ protein is structurally present in the microsomal membranes or represents cytosolic contamination remains uncertain. Identification of the anti-LC1 target antigen will clarify its relationship with CYP2D6 and will offer a more specific test for anti-LC1 detection.

Anti-LC1 has been proposed as a more specific marker of type 2 autoimmune hepatitis than anti-LKM1, since its presence was never associated with anti-HCV positivity in the original report. This finding was confirmed only in the paediatric subset of our patients, however, while a substantial proportion of the adults do have markers of HCV infection. For the purposes of type 2 autoimmune hepatitis diagnosis, the specificity of anti-LC1 is therefore similar to that of anti-LKM1. The overall picture of anti-LKM1 or anti-LC1 positive autoimmune hepatitis or both, is that of a childhood-juvenile disease with a peculiar autoantibody spectrum and biochemical and histological changes similar to those of the classic anti-nuclear/anti-actin positive autoimmune hepatitis. The relation between antiLC1 and HCV remains uncertain and its importance has still to be established.

1 Homberg JC, Abuaf N, Bernard O, Islam S, Alvarez F, Khalil SH, et al. Chronic active hepatitis associated with anti liver/kidney microsome antibody type 1: a second type of 'autoimmune' hepatitis. Hepatology 1987; 7: 1333-9.

2 Lenzi M, Ballardini G, Fusconi M, Cassani F, Selleri L, Volta U, et al. Type 2 autoimmune hepatitis and hepatitis $\mathrm{C}$ virus infection. Lancet 1990; 335: 258-9. 
3 Fusconi M, Lenzi M, Ballardini G, Miniero R, Cassani F, Zauli $\mathrm{D}$, et al. Anti-HCV testing in autoimmune hepatitis and primary biliary cirrhosis. Lancet 1990; 336: 823

4 Garson JA, Lenzi M, Ring C, Cassani F, Ballardini G, Briggs $M$, et al. Hepatitis $C$ viraemia in adults with type 2 autoimmune hepatitis. $\mathcal{F}$ Med Virol 1991; 34: 223-6.

5 Lunel F, Abuaf N, Frangeul L, Grippon P, Perrin M, Le Lunel F, Abuaf N, Frangeul L, Grippon P, Perrin M, Le
Coz Y, et al. Liver/kidney microsome antibody type 1 and hepatitis C virus infection. Hepatology 1992; 16: 630-6.
Martini E, Abuaf N, Cavalli F, Durand V, Johanet C, Homberg JC. Antibody to liver cytosol (anti-LC1) in patients with autoimmune chronic hepatitis type 2 . Hepatology 1988; 8: 1662-6.

7 Abuaf N, Johanet C, Chretien P, Soulier E, Laperche S, Homberg JC. Characterization of the liver cytosol antigen type 1 reacting with autoantibodies in chronic active hepatitis. Hepatology 1992; 16: 892-8.

8 Levy CM, Popper H, Sherlock S. Diseases of the liver and biliary tract. Standardization of numenclature, diagnostic criteria and diagnostic methodology. Chicago: Year Book Medical Publisher, 1967.

9 Garson JA, Ring CJA, Tuke PW. Improvement of HCV genome detection with 'short' PCR products. Lancet 1991; 338: 1466-7.

10 Lenzi M, Fusconi M, Selleri L, Caselli A, Cassani F, Bianchi FB, et al. Counterimmunoelectrophoresis (CIE) for the detection of anti-liver-kidney microsome (LKM) for the detection of anti-liver-kidney microsome (LKM) antibodies in the sera of patients with chro

11 Fusconi M, Baum H, Caselli A, Cassani F, Ballardini G, Lenzi $M$, et al. Demonstration of peptide-specific and cross-reactive epitopes in proteins reacting with antimitochondrial antibodies of primary biliary cirrhosis. 7 Hepatol 1992; 15: 162-9.

12 Zanger UM, Hauri HP, Loeper J, Homberg JC, Meyer UA. Antibodies against human cytochrome P-450dbl in autoimmune hepatitis type II. Proc Natl Acad Sci USA 1988; 85: 8256-60. 